\title{
Apoptosis of neurons and oligodendrocytes in the spinal cord of spinal hyperostotic mouse (twy/twy): possible pathomechanism of human cervical compressive myelopathy
}

\author{
Kenzo Uchida $\cdot$ Hideaki Nakajima $\cdot$ Shuji Watanabe $\cdot$ Takafumi Yayama $\cdot$ \\ Alexander Rodriguez Guerrero • Tomoo Inukai • Takayuki Hirai • \\ Daisuke Sugita $\cdot$ William E. Johnson $\cdot$ Hisatoshi Baba
}

Received: 5 January 2011/Revised: 14 August 2011/Accepted: 8 September 2011/Published online: 21 September 2011

(C) The Author(s) 2011. This article is published with open access at Springerlink.com

\begin{abstract}
Introduction Cervical compressive myelopathy is the most serious complication of cervical spondylosis or ossification of the posterior longitudinal ligament (OPLL) and the most frequent cause of spinal cord dysfunction. There is little information on the exact pathophysiological mechanism responsible for the progressive loss of neural tissue in the spinal cord of such patients. In this study, we used the spinal hyperostotic mouse (twy/twy) as a suitable model of human spondylosis, and OPLL to investigate the cellular and molecular changes in the spinal cord. Mutant twy/twy mouse developed ossification of the ligamentum flavum at $\mathrm{C} 2-\mathrm{C} 3$ and exhibited progressive paralysis.

Materials and methods The mutant twy/twy mice, aged 16 and 24 weeks, were used in the present study. The cervical spinal cord was analyzed histologically and immunohistochemically.

Results We observed that a significant correlation between the proportion of apoptotic oligodendrocytes in the compressed area of the spinal cord and the magnitude of cord compression. Immunohistochemical analysis indicated overexpression of TNFR1, CD95, and $\mathrm{p} 75^{\mathrm{NTR}}$ in the
\end{abstract}

Electronic supplementary material The online version of this article (doi:10.1007/s00586-011-2025-x) contains supplementary material, which is available to authorized users.

K. Uchida $(\bowtie) \cdot$ H. Nakajima $\cdot$ S. Watanabe $\cdot$ T. Yayama · A. R. Guerrero - T. Inukai - T. Hirai - D. Sugita - H. Baba Department of Orthopaedics and Rehabilitation Medicine, Faculty of Medical Sciences, University of Fukui,

Matsuoka Shimoaizuki 23-3, Eiheiji, Fukui 910-1193, Japan

e-mail: kuchida@u-fukui.ac.jp

W. E. Johnson

Life and Health Sciences, Aston University, Aston Triangle, Birmingham B4 7ET, UK twy/twy mice, which was localized by the immunofluorescence in the neurons and oligodendrocytes.

Conclusion The expression of such factors seems to play at least some role in the apoptotic process, which probably contributes to axonal degeneration and demyelination in the $t w y / t w y$ mice spinal cords with severe compression.

Keywords Apoptosis - Neurons - Spinal cord ·

Spinal hyperostotic mouse $(t w y / t w y) \cdot$ Chronic compression

\section{Introduction}

Compression of the spinal cord may compromise its function and ultimately lead to the appearance of neurological dysfunction and the development of myelopathy, which is also closely correlated with presence of dynamic factors including segmental instability during the spine movement. Cervical compressive myelopathy is the most serious complication of cervical spondylosis and ossification of the posterior longitudinal ligament (OPLL). Mechanical compression and restriction of the cervical spinal cord during the spine movement may result in gait clumsiness, paraesthesia in the hands, gait disturbance as well as signs of posterior and pyramidal column dysfunction; leading eventually to tetraplegia or tetraparesis. Cadaver studies reported that the initial insult could be infarction of the gray matter due to compromise of the spinal cord microvasculature originating at the compression site itself; followed by flattening of the anterior horns, cavity formation, ascending demyelination in the posterior columns, descending demyelination in the lateral columns and proliferation of hyalinized small blood vessels $[9,16$, 30]. Since it is difficult to properly estimate and follow the progression of these changes in humans and animal 
experimental settings, considerable uncertainty exists regarding the molecular mechanisms responsible for the demyelination that takes place in these disorders, and for the progressive loss of oligodendrocytes and neurons. Such problem is partly related to the lack of an appropriate animal model for investigating the effects of long-term mechanical compression and restriction of the spinal cord.

In a series of studies [3, 4, 23-27], we examined this issue experimentally using the tiptoe-walking Yoshimura $(t w y / t w y)$ mouse, a unique animal that develops spontaneous spinal cord compression without any other reported genetic difference in the anatomy or physiology of the spinal cord that may contribute to the resulting myelopathic syndrome; therefore, directly correlating the clinical behavior to the compression alone, eliminating the multiple factors already mentioned, that may alter the results of our observation. The twy/twy mouse is thus suitable for investigating the effects of chronic mechanical compression of the spinal cord, produced without any artificial manipulation of the cord $[3,18]$. Using these mice, we reported previously a progressive reduction in the number of anterior horn cells when the transverse remnant area of the spinal cord decreased to $\leq 70 \%$ of the control [3, 4], decreased usage of neurotrophins in autocrine and paracrine interactions [23, 24], and presence of accidental and apoptotic dying spinal cord cells [28, 29]. However, the correlation between spinal cord damage and neural cell apoptosis is not fully understood.

The present study was thus designed to investigate the localization of apoptotic cells, particularly neurons and oligodendrocytes, within the chronically compressed twy/ twy mouse spinal cord as well as the potential role of tumor necrosis factor receptor 1 (TNFR1), CD95 and $\mathrm{p} 75^{\mathrm{NTR}}$ with neuronal and oligodendroglial apoptosis.

\section{Materials and methods}

\section{Animal model}

Experiments were conducted in $28 t w y / t w y$ mice (Central Institute for Experimental Animals, Kawasaki, Japan), aged $16(n=9)$ and 24 weeks $(n=19)$ and with a mean body weight of $29.5 \pm 7.3 \mathrm{~g}( \pm \mathrm{SD})$. Mutant $t w y / t w y$ mice were maintained by brother-sister mating of heterozygous Institute of Cancer Research (ICR) mice $(+/ t w y)$. The disorder is inherited in an autosomal recessive manner and the homozygous hyperostotic mouse is identified by a characteristic tip-toe walking at 6-8 weeks of age, although no congenital neurological abnormalities are detected at that age. The spontaneous calcified deposits particularly in the atlantoaxial membrane grow progressively with age, causing profound motor paresis later in
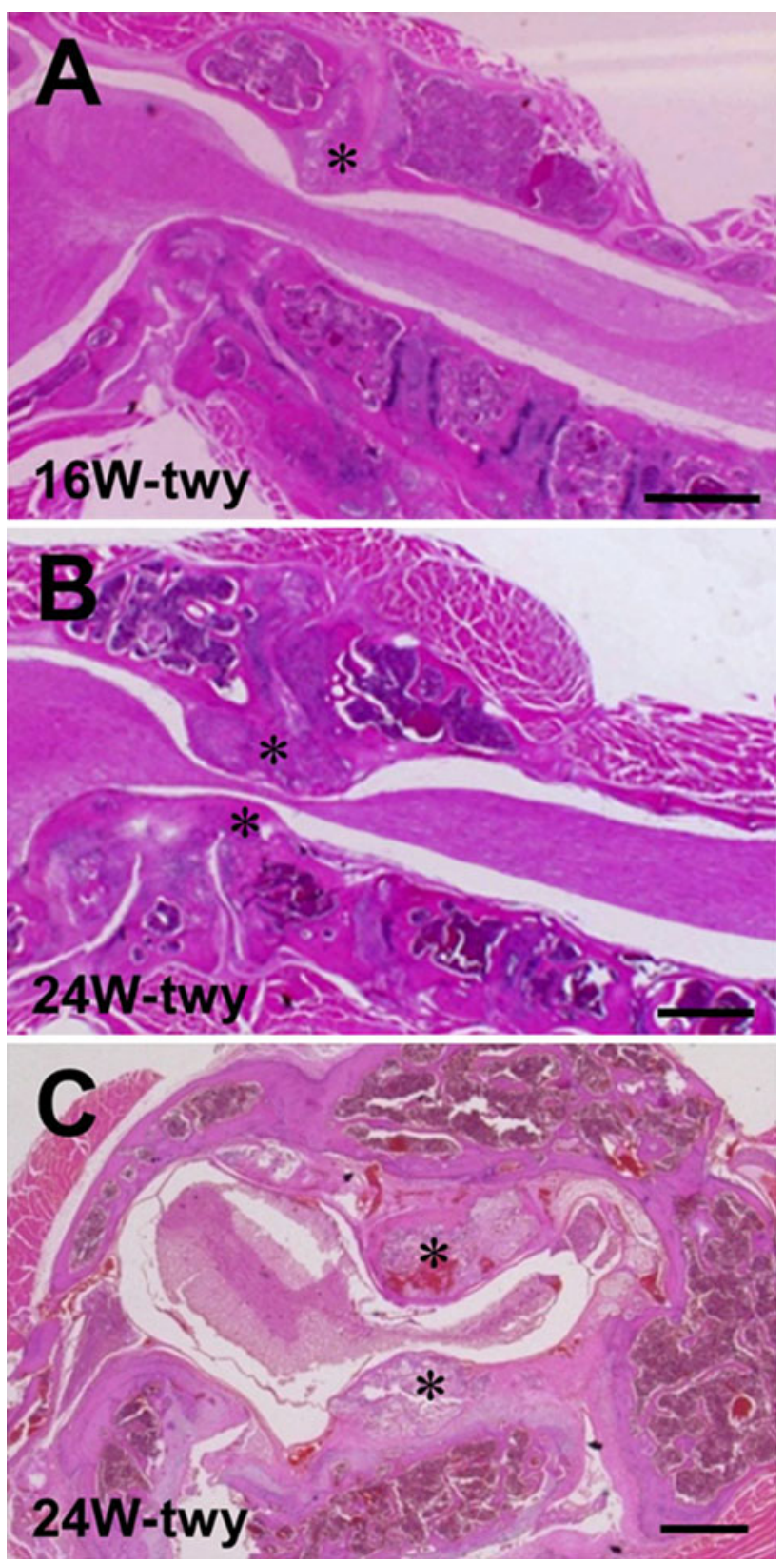

Fig. 1 Photographs showing representative hematoxylin and eosin (H\&E)-stained sagittal (a, b) and transaxial (c) sections of the cervical spine and spinal cord in 16-week-old (a) and 24-week-old twy/twy mice $(\mathbf{b}, \mathbf{c})$. Calcified lesions originating from atlantoaxial membrane in $t w y / t w y$ mice grow progressively with age, compressing the spinal cord between $\mathrm{C} 2$ and $\mathrm{C} 3$ segments laterally or posteriorly. Asterisk calcified lesions. Scale bar $500 \mu \mathrm{m}(\mathbf{a}, \mathbf{b}), 200 \mu \mathrm{m}$ (c)

life. Figure 1 shows hematoxylin and eosin (H\&E) stained sections of cervical spinal cord in 16-week-old (Fig. 1a) and 24-week-old (Fig. 1b, c) twy/twy mice. According to previous papers that analyzed the compressed transverse remnant area of the spinal cord (TRAS, \%) using transaxial serial sections [3, 25], mice were divided into two groups based on the value of TRAS\%: moderate compression 
group (TRAS\% between 50 and 70\%); and severe compression group (TRAS\% $\leq 50 \%$ ) in this study. ICR mice, age-matched with the $t w y / t w y$ mice, were used as controls $(n=12)$ [3, 18]. The Ethics Review Committee for Animal Experimentation of Fukui University approved the experimental protocol.

Histology and measurement of demyelination in the spinal cord

Sections of the spinal cord were obtained for immunohistochemistry after intracardial perfusion were dehydrated through a graded ethanol series, and embedded in paraffin. They were then cut into $10-\mu \mathrm{m}$ thick sections, deparaffinized in xylene and stained with H\&E and luxol fast blue (LFB). For semi-quantitative analysis of demyelination, the LFB-positive areas in the ventro-lateral funiculus were analyzed by a color image analyzer (MacSCOPE; Mitani, Fukui, Japan). An area was considered LFB-positive area when the density significantly exceeded the threshold of the background; being calculated as percent cross-sectional area of the residual tissue [19].

Terminal deoxynucleotidyl transferase (TdT)-mediated dUTP-biotin nick end labeling (TUNEL) staining

Immediately after perfusion, the cervical cord was removed en bloc, postfixed, and then embedded in paraffin. Samples were cut in $4 \mu \mathrm{m}$-thick serial transverse sections. Deoxyribonucleic acid (DNA) fragmentation was detected by the TUNEL method using the ApopTag Peroxidase In Situ Apoptosis Detection kit (Chemicon International, Temecula, CA). The procedures used were performed as described in the kit manual. Color was developed using 3,3'-diaminobenzidine tetrachloride. Finally, the sections were counterstained with methyl green.

Immunoblot analysis

After cardiac arrest, the cervical spinal cord was immediately removed en bloc and stored in liquid nitrogen. The sample was solubilized in RIPA buffer, homogenized and then stored at $-80^{\circ} \mathrm{C}$. The protein concentration was analyzed by Bio-Rad DC protein assay kit (No. 500-0116, BioRad Laboratories, Hercules, CA). Total protein $(80 \mu \mathrm{g} /$ lane) was subjected to sodium dodecylsulfate polyacrylamide gel (15\%) electrophoresis (SDS-PAGE) and transferred onto polyvinylidene difluoride membrane in a semidry blot apparatus. The membranes were then washed twice in PBS, subsequently reacted with anti-TNFR1 (1:200, rabbit IgG; Santa Cruz Biotechnology, Santa Cruz, CA), anti-CD95 (1:1,000, rabbit IgG; Abcamn plc,
Cambridge, UK) and anti-p $75^{\mathrm{NTR}}(1: 10$; rabbit $\mathrm{IgG}$; $\mathrm{Ab}-$ camn plc) diluted overnight at $4{ }^{\circ} \mathrm{C}$ sequentially by antirabbit IgG antibody and avidin-biotinylated peroxidase complex (1:200; Envision ${ }^{\mathrm{TM}}$ System-HRP Labeled Polymer, Dako Cytomation, Carpenteria, CA) for $3 \mathrm{~h}$. After triple washing in 0.1 M PBS, the membrane was immersed and then subjected to radiography to visualize the peroxidase activity and thus level of antibody-binding. To quantify the relative level of expression of TNFR1, CD95 and $\mathrm{p} 75^{\mathrm{NTR}}$ in ICR and twy/twy mice spinal cord, we analyzed the density of the bands on the photographic film with a densitometer using the NIH imaging software (ver. $1.59 / \mathrm{ppc}$ ). Data were expressed in relative values as a semiquantitative data, representing the ratio of each band density to $\beta$-tubulin (1:500, rabbit IgG; Abcamn plc).

\section{Double immunofluorescence staining}

To identify the type of apoptotic cells, double immunofluorescence staining was performed using frozen sections. Serial $25 \mu \mathrm{m}$-thick transverse frozen sections were treated with $0.1 \mathrm{M}$ TRIS-HCl buffer (pH 7.6). For immunofluorescence staining, the sections were incubated at $4{ }^{\circ} \mathrm{C}$ with anti-TNFR1 antibody (1:100, rabbit $\mathrm{IgG}$; Santa Cruz Biotechnology), anti-CD95 antibody (1:50, rabbit $\mathrm{IgG}$; Abcamn plc), and anti-p $75^{\text {NTR }}$ polyclonal antibody (1:100, rabbit IgG; Abcamn plc). The secondary antibodies were donkey anti-gout antibody Alexa Flour ${ }^{\circledR}$ 488/fluoresceinconjugated antibody (1: 250; Molecular Probes, Eugene, OR), and goat anti-rabbit Alexa Flour ${ }^{\circledR}$ 488/fluoresceinconjugated antibody (1:250; Molecular Probes) for $1 \mathrm{~h}$ at room temperature. For double immunofluorescence staining, the sections were further incubated with anti-neuronal nuclei monoclonal antibody (code No. MAB377, NeuN, 1:100, mouse IgG; Chemicon International), and anti-oligodendrocyte monoclonal antibody (code No. MAB1580, RIP, 1:100, mouse IgG; Chemicon International). The sections were then incubated with goat anti-mouse Alexa Flour $^{\circledR}$ 568-conjugated antibody (1:250; Molecular Probes). The immunostained cells were visualized under confocal microscope equipped with a 15-mWatt crypton argon laser (model TCS SP2, Leica Instruments, Nussloch, Germany).

Statistical analysis

All values are expressed as mean \pm SD. Differences between groups were examined for statistical significance using the paired $t$ test. A $P$ value $<0.05$ denoted the presence of a significant difference. The above tests were conducted using The Statistical Package for Social Sciences software version 11.0 (SPSS, Chicago, IL). 


\section{Results}

Histological evaluation of the mechanically compressed spinal cord

Luxol fast blue staining of the spinal cord (between $\mathrm{C} 2$ and C3 dorsal roots; the site of maximal compression) showed spongy necrosis spreading over the entire section of the spinal cord of the 16 and 24 weeks twyltwy mice but not the ICR mice ( $n=4$ in each group) (Fig. 2a). The differences were significant, especially in the marginal areas of the anterior and lateral columns. Further examination showed separation of the myelin sheath from the axon and axonal swelling and deformity; however, there was no severe degeneration, such as vascular degeneration or spongy degeneration, in the areas of compression. The percentage of the cross-sectional area of residual tissue was decreased with age, being significantly smaller than in the ICR mice (Fig. 2b).

TUNEL staining in the twy/twy mouse spinal cord

Figure 3a shows the topographic distribution of TUNELpositive cells in the chronically compressed spinal cord of 16 and 24 weeks $t w y / t w y$ mice ( $n=4$ in each group) examined by the TUNEL method. No TUNEL-positive cells were identified in both the grey and white matters of the control ICR mice spinal cord $(n=2)$. In contrast, TUNEL-positive cells were found in the gray and white matter in 16 weeks twy/twy mice. In comparison, fewer TUNEL-positive cells were found in 24 weeks $t w y / t w y$ mice particularly in the anterior horn, though these cells remained abundant in the anterior columns. Figure $3 \mathrm{~b}$ shows the results of comparative quantitative analysis of TUNEL-positive cells per sections in the anterior horn and anterior column at the maximal compressed spinal cord level in 16 and 24 weeks twy/twy mice ( $n=4$ in each group). In the spinal cord of 24 weeks $t w y / t w y$ mice with severe compression, the number of TUNEL-positive cells was significantly higher in the anterior column compared with moderate compression mice.

Differences in expression of apoptotic signals between $t w y / t w y$ and ICR mice

We evaluated the differences in the expression of various apoptotic signals between 24 weeks twy/twy mice $(n=3)$ and ICR $(n=3)$ mice by immunoblot analysis of the spinal cord. TNFR1, CD95, and p75 ${ }^{\mathrm{NTR}}$ were overexpressed in twy/twy mice but not in ICR mice (Fig. 4a). Semi-quantitative analysis confirmed increased immunoreactivity to TNFR1, CD95, and p75 ${ }^{\mathrm{NTR}}$ in twy/twy mice (Fig. 4b).

In sections double-stained for TNFR1, CD95, and p75 ${ }^{\text {NTR }}$ with NeuN and RIP, a number of double-stained cells were identified in the gray and white matters of 24-week-old $t w y / t w y$ mice $(n=6)$. Although the number of neurons (gray matter) was lower in $t w y / t w y$ mice than in ICR mice $(n=3)$, the expression of TNFR1, CD95, and $\mathrm{p} 75^{\mathrm{NTR}}$ was mainly noted in the abundant oligodendrocytes (white matter) (Fig. 4c).

\section{Discussion}

Previous investigators have characterized the pathological features of chronically compressed spinal cords of patients
Fig. 2 Photographs showing representative LFB staining of the ventral microcystic cavity in 16 and 24 weeks twy/twy and ICR mouse. Spotted white holes caused by separation of myelin sheaths from the axons in the anterior and lateral columns in twy/twy mouse. Note also swelling and deformity (arrow heads) of axons particularly in the anterior columns in $t w y / t w y$ mice (a). The percentage of the cross-sectional area of residual tissue was decrease with age in twy/twy mice and, being significantly smaller when compared with ICR mice (b). Data are mean $\pm \operatorname{SEM}(n=4)$ $* P<0.05$
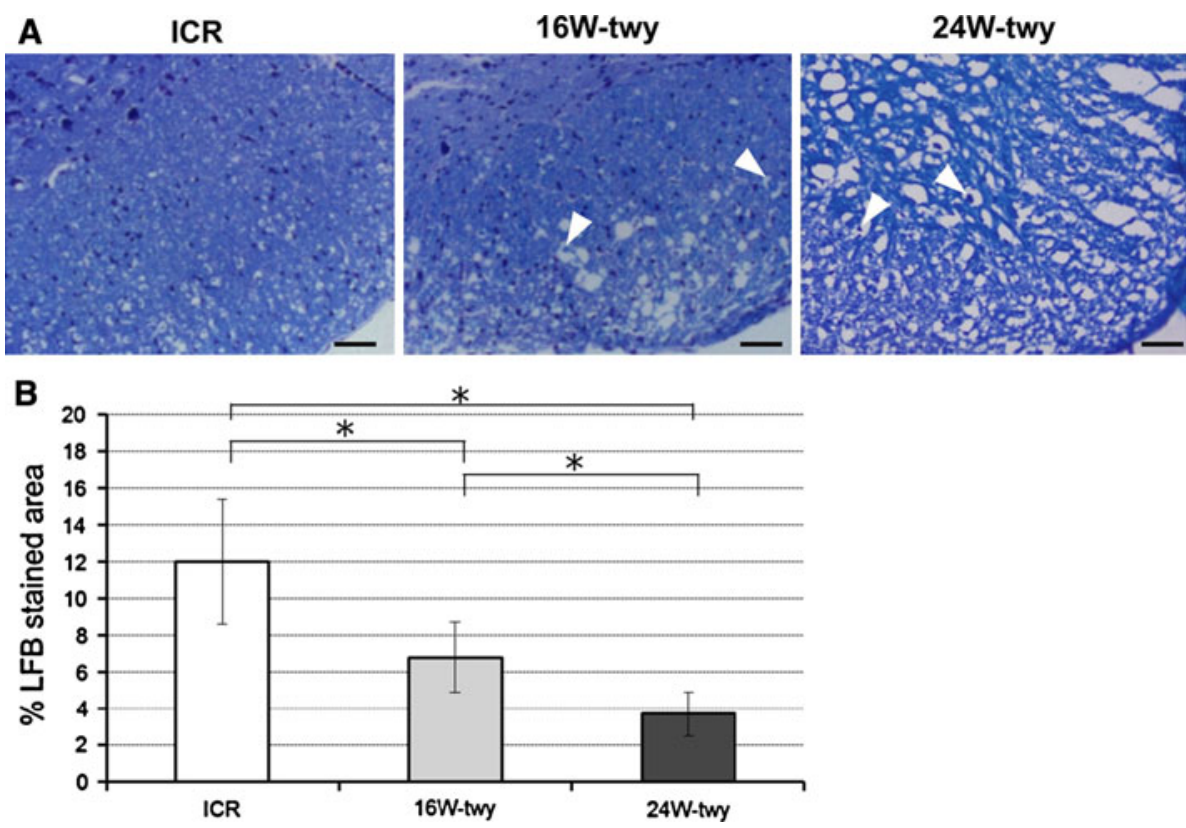
Fig. 3 Photomicrographs of terminal deoxynucleotidyl transferase (TdT)-mediated dUTP nick-end labeling (TUNEL) staining in representative control ICR (left column) mice and 16 weeks (middle column) and 24 weeks (right column) twy/twy spinal cord (a). Quantification of the number of TUNEL-positive cells at $\mathrm{C} 1-\mathrm{C} 2$ vertebral level of the 16 weeks $t w y / t w y$ mice (moderate compression) and 24 weeks twy/twy mice (severe compression). The number of TUNEL-positive cells was higher in the anterior column in 24 weeks $t w y / t w y$ mice compared with 16 weeks twy/ twy mice. Black arrows representative TUNEL-positive cells. Scale bar $50 \mu \mathrm{m}$. Data are mean $\pm \operatorname{SEM}(n=4)$.

$* P<0.05$
A

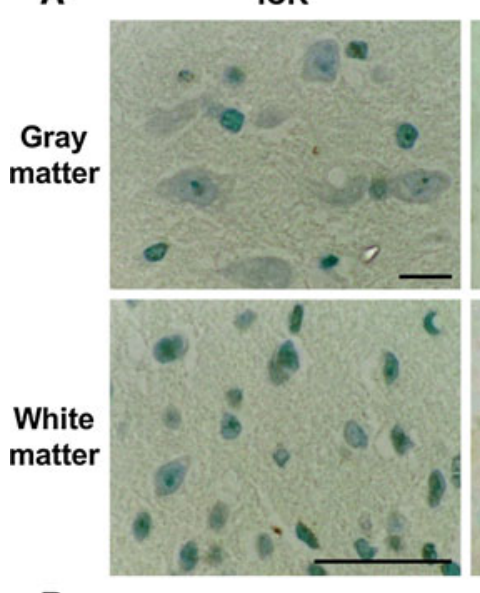

ICR

16W-twy
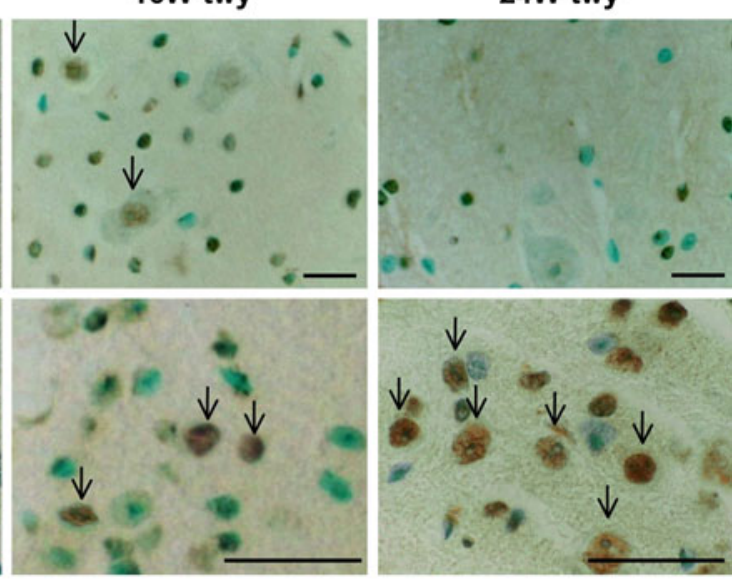

B

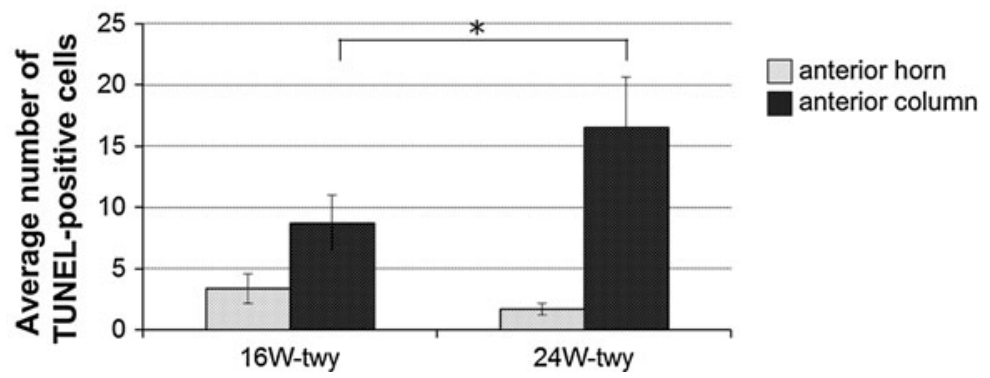

with cervical myelopathy secondary to spondylosis or OPLL $[9,16,30]$. These studies indicated that spinal cord mechanical compression is characterized by the loss and exfoliation of anterior horn neurons with progressive spongy degeneration and demyelination in the white matter. In our previous publications, we observed a significant reduction in the number of remaining surviving neurons (Nissl stainpositive motoneurons) with reduction of TRAS of the twy/twy spinal cord to $\leq 70 \%$ of that of the control $[3,4]$. Moreover, we also reported that the extent of demyelination and Wallerian degeneration in the white matter increased proportionately with the magnitude of spinal cord compression [25]. In the present study, examination of LFBstained sections of the cervical spinal cord of the twy/twy mouse showed features of spongy necrosis over the entire section of the spinal cord, especially in the marginal areas of the anterior and lateral columns, compared with the ICR mice. We also found a clear decrease in TUNEL-positive cell count in both the anterior horn of the grey matter and the anterior column of the white matter in the maximally compressed spinal cord segment of the 24-week-old twy/twy mice with severe compression. Although TUNEL staining is not specific to apoptosis [11], because the staining also reflects necrosis, our finding suggests that neuronal loss in the anterior horn, after grey matter atrophy or together with spongy degeneration and demyelination of the white matter of twy/twy mouse spinal cord, is likely to be due to apoptotic death of neurons and glia.
After acute spinal cord injury, apoptosis of neurons and glial cells occurs rapidly at the level and vicinity of the traumatic insult, leading to a secondary pathologic cascade of neural injury. Several groups have concluded that neuronal cell apoptosis is the underlying process of spinal cord damage after traumatic injury [7, 10, 14]. Another study suggested the role of mitogen activated protein-kinase cascade in neuronal cell apoptosis of twy/twy mice, in addition to other yet unknown mechanism(s) [17]. In spinal cord injury, apoptotic oligodendrocytes are found along the spinal cord longitudinal axis both proximally and caudally far from the level of injury, but most significantly at and around the level of injury [1, 13, 19]. It has been reported that extensive damage of oligodendrocytes and neurons occurs initially at the site of trauma, followed by a second wave of injury, mainly evidenced by apoptotic oligodendrocytes in the white matter, in the following seven days; which spreads both proximally and caudally from the initial point of insult [14]. Axonal damage is followed by depletion of neurotrophic factors, which leads to apoptosis of oligodendrocytes present in the area distal to the spinal cord injury site [7]. A strong correlation has been found between the delayed axonal demyelination that follows spinal cord injury and apoptosis of oligodendrocytes [13]. In the present study, immunocytochemistry of double stained sections indicated that most of the apoptotic cells were oligodendrocytes. Though insignificant when compared to the acute spinal cord injury, the longitudinally 

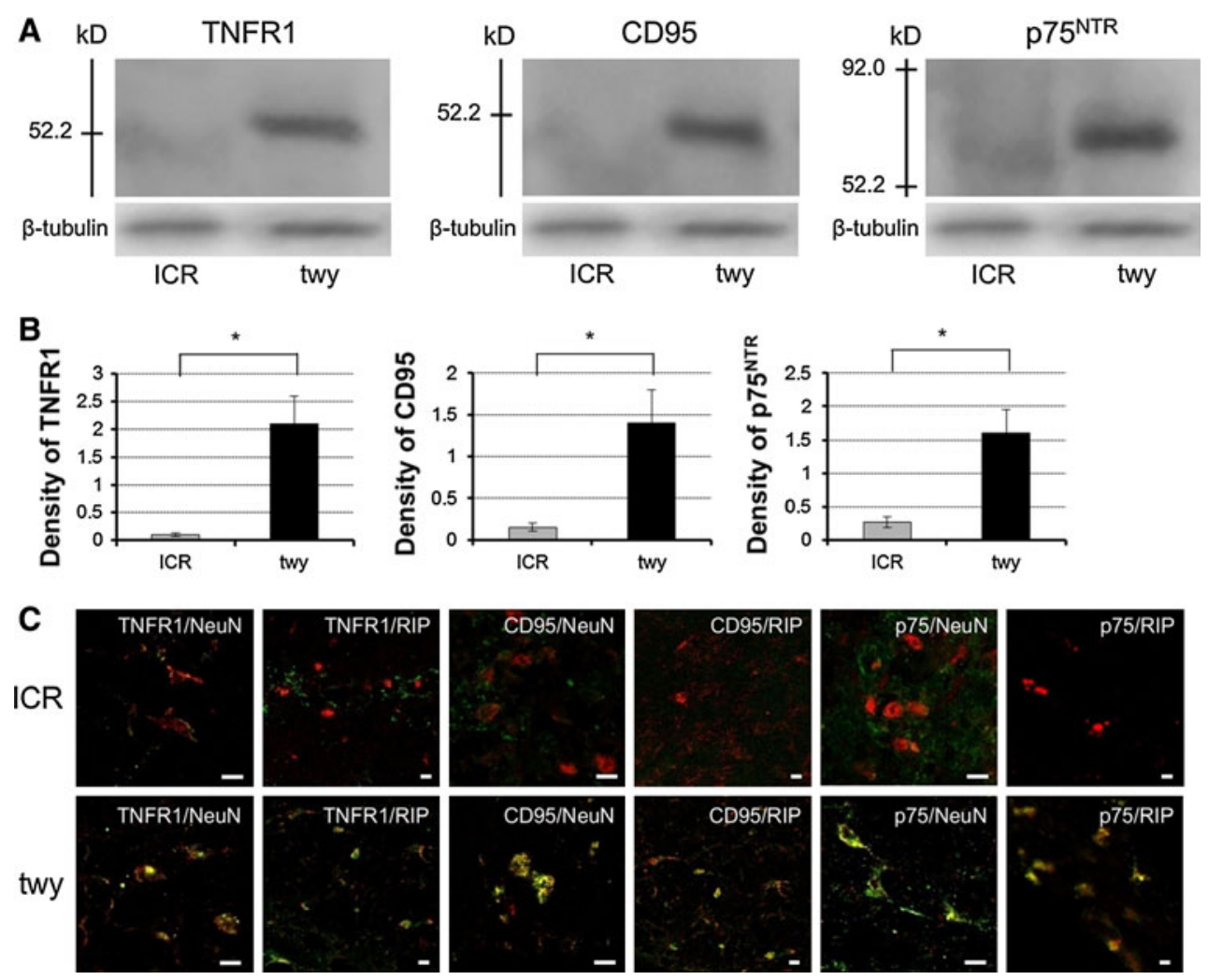

Fig. 4 Immunoblot analysis showing expression of TNFR1, CD95 and $\mathrm{p} 75^{\mathrm{NTR}}$ (a) and photomicrographs of double-staining immunofluorescence (c). The intensity of the band in 24 weeks $t w y / t w y$ mice (upper right on each panel, a) was significantly increased compared to that in ICR mice. Graphs indicate the band intensities relative to that of $\beta$-tubulin (b). The intensity of TNFR 1 , CD95 and $\mathrm{p} 75^{\mathrm{NTR}}$ in the twy/twy mice was significantly higher than that of ICR mice. Data are mean $\pm \operatorname{SEM}(n=3)$. ${ }^{*} P<0.05$. Photomicrographs show representative double-stained immunofluorescence in the gray and white matter of 24 weeks $t w y / t w y$ and ICR mouse at the site between C2 and $\mathrm{C} 3$ dorsal roots (maximal compression site in $t w y / t w y$ mouse) for TNFR1/NeuN, /RIP, CD95/NeuN, /RIP and $\mathrm{p} 75^{\mathrm{NTR}} / \mathrm{NeuN}$, /RIP. Note the double-positive cells in twy/twy mice. Scale bar $10 \mu \mathrm{m}$ (c)

TNF- $\alpha$ [8], which seems to trigger apoptosis of oligodendrocytes [12]. A previous study suggested that apoptosis of oligodendrocytes may be induced by activated microglia through the secretion of various cytotoxic factors, including TNF- $\alpha$, in response to axonal regeneration. It also has been reported that oligodendrocytes and possibly phagocytic microglia or macrophages comprised the population of apoptotic cells following spinal cord injury [20].

Double immunofluorescence staining in this study also indicated the expression of TNFR1, CD95 and $\mathrm{p} 75^{\mathrm{NTR}}$ in local cells including neurons and oligodendrocytes, while apoptotic neurons and oligodendrocytes were identified by TUNEL staining in the segment with the most severe cord compression in the $t w y / t w y$ mice. These results suggest the involvement of certain mechanisms in upregulation of inflammatory cytokines, including TNFR1, and that mechanical compression-induced expression of CD95 and p $75^{\mathrm{NTR}}$ may closely contribute to apoptosis, particularly that of neurons and oligodendrocytes in the severe spinal cord compression observed in twy/twy mouse. These findings seem to follow a similar pattern to the human cervical 
compressive myelopathy, which may validate the use of this animal model for the comparative study of such pathology in humans; making it suitable for the future assessment of the efficacy of the multiple therapeutics used in our patients as well as the study of the recovery mechanisms; in order to finally increase our knowledge of the human condition as our ultimate goal.

In conclusion, the present study demonstrated increased numbers of TUNEL-positive neurons in the gray matter and oligodendrocytes in the white matter of the spinal cord of the twy/twy mouse with progressive mechanical compression. Furthermore, the number of these cells increased with the magnitude of compression. Our immnohistochemical findings suggest that TNFR1, CD95 and $\mathrm{p} 75^{\mathrm{NTR}}$ seem to play at least some role in the apoptotic process of neurons and oligodendrocytes, which probably contributes to axonal degeneration and demyelination in the $t w y / t w y$ mouse spinal cord with severe compression.

Acknowledgments This work was supported in part by Grant-inAid to $\mathrm{HB}, \mathrm{HN}$ and $\mathrm{KU}$ for General Scientific Research of the Ministry of Education, Science and Culture of Japan (grants numbers C17591558, B18390411, B21791389, and B22390287). This work was also supported in part by grants to HB from the Investigation Committee on Ossification of the Spinal ligaments, the Public Health Bureau of the Japanese Ministry of Labor, Health and Welfare (2005-2010).

Conflict of interest The authors declare no conflict of interest.

Open Access This article is distributed under the terms of the Creative Commons Attribution Noncommercial License which permits any noncommercial use, distribution, and reproduction in any medium, provided the original author(s) and source are credited.

\section{References}

1. Abe Y, Yamamoto T, Sugiyama Y et al (1999) Apoptotic cells associated with Wallerian degeneration after experimental spinal cord injury: a possible mechanism of oligodendroglial death. J Neurotrauma 16:945-952

2. Ashkenazi A, Dixit VM (1998) Death receptor: signaling and modulation. Science 281:1305-1308

3. Baba H, Maezawa Y, Imura S et al (1996) Quantitative analysis of the spinal cord motoneuron under chronic compression: an experimental observation in the mouse. J Neurol 243:109-116

4. Baba H, Maezawa Y, Uchida K et al (1997) Three-dimensional topographic analysis of spinal accessory motoneurons under chronic mechanical compression: an experimental study in the mouse. J Neurol 244:222-229

5. Casha S, Yu WR, Fehlings MG (2001) Oligodendroglial apoptosis occurs along degenerating axons and is associated with FAS and p75 expression following spinal cord injury in the rat. Neuroscience 103:203-218

6. Chu GK, Yu W, Fehlings MG (2007) The p75 neurotrophin receptor is essential for neuronal cell survival and improvement of functional recovery after spinal cord injury. Neuroscience 148:668-682

7. Crowe MJ, Bresnahan JC, Shuman SL, Masters JN, Beattie MS (1997) Apoptosis and delayed degeneration after spinal cord injury in rats and monkeys. Nat Med 3:73-76

8. Inukai T, Uchida K, Nakajima $H$ et al (2009) Tumor necrosis factor-alpha and its receptors contribute to apoptosis of oligodendrocytes in the spinal cord of spinal hyperostotic mouse $(t w y / t w y)$ sustaining chronic mechanical compression. Spine 34:2848-2857

9. Kameyama T, Hashizume Y, Ando T et al (1995) Spinal cord morphology and pathology in ossification of the posterior longitudinal ligament. Brain 118:263-278

10. Katoh K, Ikata T, Katoh S et al (1996) Induction and its spread of apoptosis in rat spinal cord after mechanical trauma. Neurosci Lett 20:9-12

11. Koda M, Murakami M, Ino H et al (2002) Brain-derived neurotrophic factor suppresses delayed apoptosis of oligodendrocytes after spinal cord injury in rats. J Neurotrauma 19:777-785

12. Lee YB, Yune TY, Baik SY et al (2000) Role of tumor necrosis factor-alpha in neuronal and glial apoptosis after spinal cord injury. Exp Neurol 166:190-195

13. Li GL, Farooque M, Holtz A, Olsson Y (1999) Apoptosis of oligodendrocytes occurs for long distances away from the primary injury after compression trauma to rat spinal cord. Acta Neuropathol 98:473-480

14. Liu XZ, Xu XM, Hu R et al (1997) Neural and glial apoptosis after traumatic spinal cord injury. J Neurosci 17:5395-5406

15. Lowry KS, Murray SS, Coulson EJ et al (2001) Systemic administration of antisense p75(NTR) oligodeoxynucleotides rescues axotomised spinal cord neurons. J Neurosci Res 64:11-17

16. Mizuno J, Nakagawa H, Chang H-S et al (2005) Postmortem study of the spinal cord showing snake-eyes appearance due to damage by ossification of the posterior longitudinal ligament and kyphotic deformity. Spinal Cord 43:503-507

17. Nakahara S, Yone K, Sakou T et al (1999) Induction of apoptosis signal regulating kinase 1 (ASK1) after spinal cord injury in rats: possible involvement of ASK1-JNK and p38 pathways in neuronal apoptosis. J Neuropathol Exp Neurol 58:442-450

18. Okawa A, Nakamura I, Goto S et al (1998) Mutation in Npps in a mouse model of ossification of the posterior longitudinal ligament of the spine. Nat Genet 19:271-273

19. Shi X, Kang Y, Hu Q et al (2010) A long-term observation of olfactory ensheathing cells transplantation to repair white matter and functional recovery in a focal ischemia model in rat. Brain Res 1317:257-267

20. Shuman SL, Bresnahan JC, Beattie MS (1997) Apoptosis of microglia and oligodendrocytes after spinal cord contusion in rats. J Neurosci Res 50:798-808

21. Springer JE, Azbill RD, Knapp PE (1999) Activation of the caspase-3 apoptotic cascade in traumatic spinal cord injury. Nat Med 5:943-946

22. Takenouchi T, Setoguchi T, Yone K, Komiya S (2008) Expression of apoptosis signal-regulating kinase 1 in mouse spinal cord under chronic mechanical compression: possible involvement of the stress-activated mitogen-activated protein kinase pathways in spinal cord cell apoptosis. Spine 33:1943-1950

23. Uchida K, Baba H, Maezawa Y et al (1998) Histological investigation of spinal cord lesions in the spinal hyperostotic mouse $(t w y / t w y)$ : morphological changes in anterior horn cells and immunoreactivity to neurotrophic factors. J Neurol 245:781-793

24. Uchida K, Baba H, Maezawa $Y$ et al (2003) Increased expression of neurotrophins and their receptors in the mechanically compressed spinal cord of the spinal hyperostotic mouse (twy/twy). Acta Neuropathol 106:29-36 
25. Uchida K, Baba H, Maezawa Y, Kubota C (2002) Progressive changes in neurofilament proteins and growth-associated protein43 immunoreactivities at the site of cervical spinal cord compression in spinal hyperostotic mice. Spine 27:480-486

26. Uchida K, Nakajima H, Inukai $T$ et al (2008) Adenovirus-mediated retrograde transfer of neurotrophin-3 gene enhances survival of anterior horn neurons of $t w y / t w y$ mice with chronic mechanical compression of the spinal cord. J Neurosci Res 86:1789-1800

27. Xu K, Uchida K, Nakajima H, Kobayashi S, Baba H (2006) Targeted retrograde transfection of adenovirus vector carrying brain-derived neurotrophic factor gene prevents loss of mouse $(t w y / t w y)$ anterior horn neurons in vivo sustaining mechanical compression. Spine 31:1867-1874
28. Yamaura I, Yone K, Nakahara S et al (2002) Mechanism of destructive pathologic changes in the spinal cord under chronic mechanical compression. Spine 27:21-26

29. Yu WR, Baptiste DC, Liu T et al (2009) Molecular mechanisms of spinal cord dysfunction and cell death in the spinal hyperostotic mouse: implications for the pathophysiology of human cervical spondylotic myelopathy. Neurobiol Dis 33:149-163

30. Yu YL, Leong JC, Fang D et al (1988) Cervical myelopathy due to ossification of the posterior longitudinal ligament. A clinical, radiological and evoked potentials study in six Chinese patients. Brain 111:769-783 